\title{
Proximal Junctional Kyphosis: Diagnosis, Pathogenesis, and Treatment
}

\author{
Jaewon Lee, Ye-Soo Park \\ Department of Orthopedic Surgery, Hanyang University Guri Hospital, Hanyang University College of Medicine, Guri, Korea
}

\begin{abstract}
Proximal junctional kyphosis (PJK) is a common radiographic finding after long spinal fusion. A number of studies on the causes, risk factors, prevention, and treatment of PJK have been conducted. However, no clear definition of PJK has been established. In this paper, we aimed to clarify the diagnosis, prevention, and treatment of PJK by reviewing relevant papers that have been published to date. A literature search was conducted on PubMed using "proximal junctional", "proximal junctional kyphosis", and "proximal junctional failure" as search keywords. Only studies that were published in English were included in this study. The incidence of PJK ranges from $5 \%$ to $46 \%$, and it has been reported that $66 \%$ of cases occur 3 months after surgery and approximately $80 \%$ occur within 18 months. A number of studies have reported that there is no significantly different clinical outcome between PJK patients and non-PJK patients. One study showed that PJK patients expressed more pain than non-PJK patients. However, recent studies focused on proximal junctional failure (PJF), which is accepted as a severe form of PJK. PJF showed significant adverse impact in clinical aspect such as pain, neurologic deficit, ambulatory difficulties, and social isolation. Numerous previous studies have identified various risk factors and reported on the treatment and prevention of PJK. Based on these studies, we determined the clinical significance and impact of PJK. In addition, it is important to find a strategic approach to the proper treatment of PJK.
\end{abstract}

Keywords: Proximal junctional kyphosis; Spinal deformity; Epidemiology; Treatment; Risk factor

\section{Introduction}

Proximal junctional kyphosis (PJK) has become the greatest challenge in surgery for spinal deformity. PJK is detected by radiologic findings indicating that a pathologic problem has developed internally around the adjacent segment after a spinal fusion. PJK is not an instantaneous symptom but is considered one of various ongoing adjacent segmental problems. Some PJK patients may display no symptoms whereas others, referred to as proximal junctional failure (PJF) patients, express clinical symptoms accompanied by pain, walking disturbance, and neurologic deficit, and reoperation may be required in some severe cases [1]. Spine specialists have suggested various explanations to understand these cases of PJK. In this review, we compare and summarize the diagnosis, incidence, pathogenesis, and treatment of PJK from review of current literature, with the aim of proposing a new direction for further research into PJK.

\section{Discussion}

The authors searched papers published up to July 2015 using the PubMed databases with "proximal junctional",

\footnotetext{
Received Sep 20, 2015; Revised Sep 30, 2015; Accepted Oct 1, 2015

Corresponding author: Ye-Soo Park

Department of Orthopaedic Surgery, Hanyang University Guri Hospital, Hanyang University College of Medicine,

153 Gyeongchun-ro, Guri 11923, Korea

Tel: +82-31-560-2317, Fax: +82-31-560-8781, E-mail: hyparkys@hanyang.ac.kr
} 
Table 1. Definition of proximal junctional kyphosis

\begin{tabular}{lccl} 
Authors & Publication year & \multicolumn{1}{c}{$\begin{array}{c}\text { Study population } \\
\text { Definition }\end{array}$} \\
\hline Glattes et al. [3] & 2005 & Adult spinal deformity & $\begin{array}{l}\text { Cobb angle between the UIV and two } \\
\text { supra-adjacent vertebra } \geq 10^{\circ}\end{array}$ \\
\hline Helgeson et al. [4] & 2010 & Adolescent idiopathic scoliosis & $\begin{array}{l}\text { Cobb angle between the UIV and one } \\
\text { supra-adjacent vertebra }>15^{\circ}\end{array}$ \\
\hline 0'Shaughnessy et al. [15] & 2012 & Adult spinal deformity & $\begin{array}{l}\text { Cobb angle between the UIV and two } \\
\text { supra-adjacent vertebra } \geq 20^{\circ}\end{array}$ \\
\hline Hostin et al. [5] & 2013 & Adult spinal deformity & $\begin{array}{l}\text { Cobb angle between the UIV and two } \\
\text { supra-adjacent vertebra } \geq 15^{\circ}\end{array}$ \\
\hline
\end{tabular}

UIV, uppermost instrumented vertebra.

"proximal junctional kyphosis", and "proximal junctional failure" as the search keywords.

A total of 594 papers were found on PubMed, excluding non-English language papers and duplicated papers. This number includes only papers that discussed the incidence, definition, risk factors, treatment, and prevention of PJK. Based on this finding, 40 articles were included in this review.

\section{Definition}

In order to diagnose PJK, a proper working definition of PJK should first be established. As suggested by the terminology, an abnormal kyphotic deformity occurs at the uppermost instrumented vertebra (UIV), a finding that was observed systematically and reported for the first time by Lee et al. [2], who defined a case of PJK as "a patient with adolescent idiopathic scoliosis having kyphosis 5 degrees higher than normal at the proximal level of the instrumented fusion" after conducting posterior spinal fusion. However, the various definitions of PJK have not yet been integrated, and PJK continues to be defined in a variety of ways.

Glattes et al. [3] defined PJK as a case "showing a proximal junctional sagittal Cobb angle-which is composed of the lower endplate of the uppermost instrumented vertebra (UIV) and the upper endplate of the two supraadjacent vertebrae-some 10 degrees higher than a preoperative measurement."

Helgeson et al. [4] claimed that more than 15 degrees of abnormal kyphotic angulation should occur when PJK is measured at one adjacent vertebra above the UIV. These authors suggested that conventional measurement at two adjacent vertebrae above the UIV does not reflect a physi- ological basis, and disruption of the facet capsule and interspinous ligament were considered to be the causes of PJK.

However, Hostin et al. [5] defined PJK as "showing more than 15 degrees of angulation at two supra-adjacent vertebrae above the UIV" based on the results of a large multicenter and retrospective study. In addition, in many other papers, PJK has been defined as a case "showing more than 15 degrees of Cobb angle at two adjacent vertebrae above the UIV" [6-14]. Furthermore, O'Shaughnessy et al. [15] and Bridwell et al. [16] defined PJK as a case "showing more than 20 degrees of Cobb angle at two levels above the UIV." In particular, Bridwell et al. [16] argued that more than 20 degrees is not a standard for revision surgery of PJK, although it can be a critical cutoff value as a threshold for worse patient-reported outcomes.

Sacramento-Dominguez et al. [17] performed 152 measurements in 19 scoliosis patients and compared the reproducibility of the PJK angle at one level and two levels above the UIV. To validate the result of each measurement, the intra-surgeon concordance correlation coefficient ranged from 0.78 to 0.92 , which showed a very high degree of reproducibility, while the inter-concordance correlation coefficient ranged from 0.55 to 0.80 , showing a moderate to high degree of reproducibility. Both one level and two levels showed a positive result for reproducibility. To summarize the abovementioned findings, there is no clear definition of PJK, but based on previous studies PJK can be categorized into four classes and clinical PJK can be diagnosed based on these definitions (Table 1).

\section{Pathogenesis and risk factors}

The pathogenesis of PJK has yet to be established. Sug- 
gested mechanisms include the following: (1) extensive paraspinal muscle dissection at the upper instrumented vertebra, (2) disruption of the supraspinous and interspinous ligaments (posterior tension band), (3) improper end-vertebra selection, (4) proximal severe disc degeneration, (5) compression fracture at the most instrumented vertebra, (6) instrumentation failure at the proximal construct, and (7) facet violation $[3,18]$. In addition, many studies have investigated the risk factors of PJK in order to better understand the pathogenesis of PJK.

The following major risk factors for PJK have been suggested: older age ( $>55$ years) $[16,19,20]$; large abnormal preoperative sagittal parameters $[2,6,8,10-12,14]$; the use of pedicle screws $[4,10,12,14,21]$; thoracoplasty procedures $[10,12,14]$; greater curvature correction $[8,12,16,20,22]$; posterior and anterior-posterior spinal fusion (i.e., disruption of the posterior tension band/posterior intervertebral elements) $[6,9,11,16,19,21]$; and fusion to the lower lumbar spine and sacrum $[6,9-11,13,15]$. In addition, low bone marrow density [11] and a patient's comorbidity and high body mass index [16] are discussed as potential risk factors (Table 2). However, clear evidence supporting the number of instrumented levels and the UIV level, which are regarded as the strongest influences, is not yet available $[9,14,16,23]$.

\section{Incidence}

Hostin et al. [5] reported an incidence of PJK of 6\%, Yagi et al. [6] reported an incidence of $20 \%$ among adult scoliosis patients, Kim et al. [19] reported an incidence of 39\% after 7.8 years of follow-up, and Maruo et al. [8] reported an incidence of $41 \%$. The reported incidence in all reports ranges from $6 \%$ to $41 \%$ (Table 2). The incidence of PJK also varies depending on the level of UIV. O'Shaughnessy et al. [15] reported a lower thoracic incidence of $18.4 \%$ and upper thoracic incidence of $10 \%$.

PJK tends to appear shortly after an operation. Kim et al. [19] suggested that PJK appears within 8 weeks of surgery, whereas Yagi et al. [11] reported that $66 \%$ of PJK cases appeared within 3 months and Wang et al. [10] stated that $80 \%$ of cases of PJK could be diagnosed within 18 months.

\section{Clinical appearance and severity}

PJK can present in a spectrum from simple radiologic findings to symptoms with a significant clinical impact. Numerous studies on the differences between cases of PJK that are clinically obvious and cases with only radiological findings have been conducted.

Several studies have reported that there are no significant differences in Scoliosis Research Society scores and clinical symptoms between non-PJK patients and PJK patients $[3,6,14,24]$. In contrast to these results, Kim et al. [25] performed a large-scale study in which they analyzed 364 patients. The PJK patient group showed a significantly higher incidence of pain, with pain prevalent in $29.4 \%$ of the PJK patient group compared with only $0.9 \%$ of the non-PJK patient group. In particular, the presence of pain in the upper back was higher among PJK patients with a 12.5-fold odds ratio. Regarding this issue, Hart et al. [7] reported that PJK appears within a spectrum of disease severities from benign PJK without clinical impact to PJF, which eventually has significant adverse impact, and that $47.4 \%$ of patients with PJF underwent revision surgery.

In several studies, PJF is reported as one entity in the disease spectrum of PJK that includes kyphosis and structural failure of the body and the posterior ligament complex $[26,27]$. As such, PJF patients may experience pain, neurologic deficit, ambulatory difficulties, social isolation, and/or inability to maintain a horizontal gaze $[1,11,19,25]$. Smith et al. [28] suggested that it was necessary to pay special attention to PJF, which is crucial from the clinical perspective because adult patients with spinal deformity tend to have long constructs, but do not necessarily exhibit worse clinical outcomes.

In particular, fracture, implant failure, and myelopathy due to stenosis at the UIV or UIV+1 that appears within 6 months of an early proximal junctional failure (EPFJ) were defined [28]. The authors reported a $25 \%$ higher incidence of EPFJ, which appeared most commonly at the lower thoracic spine level and was not related to postoperative sagittal balance.

\section{Prevention}

Even more important than treatment is the prevention of PJK. In order to prevent PJK, the risk factors should be sufficiently considered before surgery. Above all, the sagittal alignment of a patient should be checked, and then the proper revision should be conducted by osteotomy depending on the flexibility or rigidity of the patient's deformity. At this point, the UIV level should be set with neu- 
Table 2. Incidence and clinical appearance of PJK

\begin{tabular}{|c|c|c|c|c|c|c|}
\hline Authors & $\begin{array}{c}\text { Publication } \\
\text { year }\end{array}$ & Study population & $\begin{array}{c}\text { No. of } \\
\text { patients }(n)\end{array}$ & $\begin{array}{l}\text { Follow-up } \\
\text { (yr, [range]) }\end{array}$ & $\begin{array}{l}\text { Incidence } \\
(\%)\end{array}$ & $\begin{array}{l}\text { Clinical difference } \\
\text { between PJK } \\
\text { and non-PJK }\end{array}$ \\
\hline Glattes et al. [3] & 2005 & Adult spinal deformity & 81 & $5.3(2-16)$ & 26 & No difference \\
\hline Kim et al. [14] & 2005 & AIS & 193 & $7.3(5-16.7)$ & 26 & No difference \\
\hline Kim et al. [19] & 2008 & Adult spinal deformity & 161 & $7.8(5-19.8)$ & 39 & $\begin{array}{l}\text { No difference, but } \\
\text { worse SRS self-image } \\
\text { score when PJK }>20^{\circ}\end{array}$ \\
\hline Hyun and Rhim [24] & 2010 & $\begin{array}{l}\text { PSO-treated patients } \\
\text { presenting with fixed } \\
\text { sagittal imbalances }\end{array}$ & 13 & $6.1(3.4-9.5)$ & 23 & - \\
\hline $\begin{array}{l}\text { Mendoza-Lattes } \\
\text { et al. [13] }\end{array}$ & 2011 & Adult spinal deformity & 54 & $2.2(1-3.5)$ & 35 & - \\
\hline Yagi et al. [6] & 2011 & Adult idiopathic scoliosis & 157 & $4.3(2-12)$ & 20 & $\begin{array}{l}\text { No difference, but } \\
\text { worse SRS and ODI } \\
\text { scores in symptomatic } \\
\text { PJK patients }\end{array}$ \\
\hline Yagi et al. [11] & 2012 & Adult idiopathic scoliosis & 76 & $7.3(5-14)$ & 22 & No difference \\
\hline $\begin{array}{l}\text { 0'Shaughnessy } \\
\text { et al. [15] }\end{array}$ & 2012 & Adult spinal deformity & 58 & 3.0 & $\begin{array}{l}U T=10.0 \\
L T=18.4\end{array}$ & No difference \\
\hline Hostin et al. [5] & 2013 & Adult spinal deformity & 1218 & - & 6 & - \\
\hline Bridwell et al. [16] & 2013 & $\begin{array}{l}\text { Adult idiopathic/ } \\
\text { degenerative scoliosis }\end{array}$ & 90 & $3.5(2-12)$ & 28 & No difference \\
\hline Kim et al. [25] & 2013 & Adult scoliosis & 364 & $3.5(2-6)$ & 40 & $\begin{array}{l}\text { Worse SRS pain } \\
\text { subscore }\end{array}$ \\
\hline Ha et al. [29] & 2013 & Adult spinal deformity & 89 & $\begin{array}{l}\mathrm{PT}=3.0(1089 \pm 286 \text { days }) \\
\mathrm{DT}=2.7(983 \pm 9832 \text { days })\end{array}$ & $\begin{array}{l}\mathrm{PT}=27 \\
\mathrm{DT}=34\end{array}$ & No difference \\
\hline Maruo et al. [8] & 2013 & Adult spinal deformity & 90 & $2.9(2-4.9)$ & 41 & - \\
\hline
\end{tabular}

PJK, proximal junctional kyphosis; AIS, adolescent idiopathic scoliosis; SRS scrore, Scoliosis Research Society score; PSO, pedicle subtraction osteotomy; ODI, Oswestry disability index; UT, upper thoracic; LT, lower thoracic; PT, proximal thoracic; DT, distal thoracic.

tral and stable vertebra in order to reduce the prevalence of revision for patients with adult deformity [30]. Making a decision on the UIV level, however, is not as simple as it sounds. If the UIV is decided at T8 or a lower level for shorter fusions, the prevalence of $\mathrm{PJK}$ might be increased $[15,16,31,32]$, whereas increasing the fusion level to the proximal level in order to prevent simple PJK could lead to perioperative complications, which could in turn cause other problems. Some studies have reported that pedicle screws increase the possibility of facet violation and the creation of a rigid construct, such that long-segment instrumentation using pedicle screws might increase the prevalence of PJK.

Helgeson et al. [4] compared the prevalence of PJK in a multicenter retrospective study. The authors compared the four groups of hook-only constructs, hybrid constructs (pedicle screws and hooks), pedicle-screw only constructs, and pedicle-screw constructs with hooks only at the most cephalic level during a 2-year follow-up, and reported that the most significant increase in PJK was observed in the group of pedicle-only constructs.

As a preventive measure, various trials to reduce the prevalence of PJK using hooks have been reported. Hassanzadeh et al. [33] used transverse process hook and pedicle screws at the UIV for patients who had already undergone more than five levels of instrumentation surgeries. After a 2-year follow-up, $29.6 \%$ of the group with pedicle screws showed symptoms of PJK, but no cases of PJK were observed in the patient group with hooks. Kim et al. [12] also reported a lower prevalence of PJK in cases where hooks rather than only pedicle screws were used.

Regarding decisions on the lowest instrumented ver- 
tebra (LIV), various factors should be considered. Some studies have argued that fusion of the sacrum is a risk factor $[6,9-11,13,15]$ and that sufficient consideration when deciding on fusion at a lower level is required. However, it must be remembered that if L5 is decided as the LIV, degeneration of the L5-S1 disc will progress and thus a revision operation may be required [34].

In addition, damage to parts of the posterior column such as the facet joint capsule or interspinous ligament during the operation must be minimized to allow it to function as a posterior tension band [21]. In the case of the osteoporotic bone, the development of not only PJK, but also of PJF, could occur because of the prevalence of compression fractures and loosening of the pedicle screw at the UIV. Therefore, prevention of PJK through osteoporosis treatment should be considered. However, the use of bisphosphonate in spinal fusion remains controversial [35], and instead the improvement in bone quality and effective establishment of bone union could be implemented using teriparatide [36,37].

Hart et al. [27] reported that use of vertebroplasty at the UIV is effective in preventing compression fractures. In their study, 15 of 28 women older than 60 years were operated on with cement augmentation, whereas the remaining 13 women were not treated; none of the former group showed signs of PJK, whereas $15.3 \%$ of the latter group displayed secondary PJK due to collapse of the vertebral body. Moreover, in their biomechanical cadaveric study, Kebaish et al. [38] reported preventive effects when they conducted vertebroplasty at both the UIV and one higher level of vertebrae. However, cement may change the load transfer and ultimately lead to the fracture and collapse of adjacent vertebrae [26]. Although these are simple case reports, it should be noted that there are also reports warning of further severe fracture with augmentation at the UIV [39].

\section{Treatment}

PJK is a simple radiologic finding and a continuously progressive disease. If it develops as symptomatic PJK it appears as a type of PJF. There are no evidence-based guidelines on the treatment of PJK. Once a patient has a problem around the proximal junction, evaluating the existence of clinical symptoms should be prioritized. If there are no symptoms prompt treatment is not required in most cases, but if severe symptoms exist or a defor- mity of the proximal junction progresses rapidly surgical treatment will be required. Hart et al. [7] suggested more specific decision-making criteria for surgery. Based on their research on 57 PJF patients, they reported the factors that most influenced PJF revision surgery were high PJK angulation, high sagittal vertical axis, trauma, and female gender. However, other commonly considered factors including soft tissue versus bony failure, patient age, level of fusion, and upper thoracic versus thoracolumbar proximal junction showed no correlation. When conducting surgical treatment, a neural decompression procedure with process of extending and realigning the instrumentation is required in most cases. If the spine is flexible, a stable level should be found at the proximal level of the UIV from a previous surgery. If the spine is rigid, the global sagittal alignment should be revised using a method of osteotomy, such as Smith-Peterson osteotomy or pedicle subtraction osteotomy. Above all, an entire spine lateral radiograph from a standing position should be taken and the fundamental causes of the problem should be determined in order to prevent any further occurrence.

\section{Conclusions}

The development of implants for spinal surgery has allowed multilevel spinal instrumentation. As a result, PJK, as one of the related complications, has received attention in recent years. The increased interest of spine surgeons in PJK has resulted in a number of research papers, and the epidemiology and risk factors associated with PJK have become known through these studies. Despite the high prevalence of PJK, a collective definition of PJK has not yet been clearly established, and further research needs to be conducted. In addition, a standardized consensus concerning the pros and cons of operating on PJK patients is required. Even though a number of studies on PJK have been conducted [40], spine surgeons continue to hold different opinions and perspectives about the treatment of PJK. Finally, further PJK guidelines and a standard classification that not only include symptoms, radiologic findings, pathogenesis, severity of PJK, treatment, and prognosis, but are also easy to understand and apply to PJK treatment, need to be elaborated.

\section{Summary}

- A clear definition of PJK has not been established, but 
it is mostly defined as a Cobb angle between the UIV and two supra-adjacent vertebra $\geq 10^{\circ}-20^{\circ}$.

- In reported cases, the incidence of PJK ranged from $6 \%$ to $41 \%$, and it was observed to appear shortly after an operation.

- $\mathrm{PJK}$ is a progressive type of disease that develops from a simple radiologic finding into symptomatic $\mathrm{PJK}$, which appears in the form of PJF that might have a catastrophic outcome.

- The risk factors for PJK are well known and acknowledged. Based on this knowledge, a precise preoperative plan should be established in order to prevent PJK.

- A standardized consensus for further understanding and treatment of PJK is required.

\section{Conflict of Interest}

No potential conflicts of interest relevant to this article are reported.

\section{References}

1. McClendon J Jr, O'Shaughnessy BA, Sugrue PA, et al. Techniques for operative correction of proximal junctional kyphosis of the upper thoracic spine. Spine (Phila Pa 1976) 2012;37:292-303.

2. Lee GA, Betz RR, Clements DH 3rd, Huss GK. Proximal kyphosis after posterior spinal fusion in patients with idiopathic scoliosis. Spine (Phila Pa 1976) 1999;24:795-9.

3. Glattes RC, Bridwell KH, Lenke LG, Kim YJ, Rinella A, Edwards C 2nd. Proximal junctional kyphosis in adult spinal deformity following long instrumented posterior spinal fusion: incidence, outcomes, and risk factor analysis. Spine (Phila Pa 1976) 2005;30:1643-9.

4. Helgeson MD, Shah SA, Newton PO, et al. Evaluation of proximal junctional kyphosis in adolescent idiopathic scoliosis following pedicle screw, hook, or hybrid instrumentation. Spine (Phila Pa 1976) 2010; 35:177-81.

5. Hostin R, McCarthy I, O'Brien M, et al. Incidence, mode, and location of acute proximal junctional failures after surgical treatment of adult spinal deformity. Spine (Phila Pa 1976) 2013;38:1008-15.

6. Yagi M, Akilah KB, Boachie-Adjei O. Incidence, risk factors and classification of proximal junctional kyphosis: surgical outcomes review of adult idiopathic scoliosis. Spine (Phila Pa 1976) 2011;36:E60-8.

7. Hart R, McCarthy I, O'brien M, et al. Identification of decision criteria for revision surgery among patients with proximal junctional failure after surgical treatment of spinal deformity. Spine (Phila Pa 1976) 2013; 38:E1223-7.

8. Maruo K, Ha Y, Inoue S, Samuel S, et al. Predictive factors for proximal junctional kyphosis in long fusions to the sacrum in adult spinal deformity. Spine (Phila Pa 1976) 2013;38:E1469-76.

9. Kim HJ, Yagi M, Nyugen J, Cunningham ME, Boachie-Adjei O. Combined anterior-posterior surgery is the most important risk factor for developing proximal junctional kyphosis in idiopathic scoliosis. Clin Orthop Relat Res 2012;470:1633-9.

10. Wang J, Zhao Y, Shen B, Wang C, Li M. Risk factor analysis of proximal junctional kyphosis after posterior fusion in patients with idiopathic scoliosis. Injury 2010;41:415-20.

11. Yagi M, King AB, Boachie-Adjei O. Incidence, risk factors, and natural course of proximal junctional kyphosis: surgical outcomes review of adult idiopathic scoliosis. Minimum 5 years of follow-up. Spine (Phila Pa 1976) 2012;37:1479-89.

12. Kim YJ, Lenke LG, Bridwell KH, et al. Proximal junctional kyphosis in adolescent idiopathic scoliosis after 3 different types of posterior segmental spinal instrumentation and fusions: incidence and risk factor analysis of 410 cases. Spine (Phila Pa 1976) 2007;32:2731-8.

13. Mendoza-Lattes S, Ries Z, Gao Y, Weinstein SL. Proximal junctional kyphosis in adult reconstructive spine surgery results from incomplete restoration of the lumbar lordosis relative to the magnitude of the thoracic kyphosis. Iowa Orthop J 2011;31:199-206.

14. Kim YJ, Bridwell KH, Lenke LG, Kim J, Cho SK. Proximal junctional kyphosis in adolescent idiopathic scoliosis following segmental posterior spinal instrumentation and fusion: minimum 5-year followup. Spine (Phila Pa 1976) 2005;30:2045-50.

15. O’Shaughnessy BA, Bridwell KH, Lenke LG, et al. Does a long-fusion "T3-sacrum" portend a worse outcome than a short-fusion "T10-sacrum" in primary surgery for adult scoliosis? Spine (Phila Pa 1976) 2012;37:884-90.

16. Bridwell KH, Lenke LG, Cho SK, et al. Proximal junctional kyphosis in primary adult deformity 
surgery: evaluation of 20 degrees as a critical angle. Neurosurgery 2013;72:899-906.

17. Sacramento-Dominguez C, Vayas-Diez R, Coll-Mesa $\mathrm{L}$, et al. Reproducibility measuring the angle of proximal junctional kyphosis using the first or the second vertebra above the upper instrumented vertebrae in patients surgically treated for scoliosis. Spine (Phila Pa 1976) 2009;34:2787-91.

18. Anderson AL, McIff TE, Asher MA, Burton DC, Glattes RC. The effect of posterior thoracic spine anatomical structures on motion segment flexion stiffness. Spine (Phila Pa 1976) 2009;34:441-6.

19. Kim YJ, Bridwell KH, Lenke LG, Glattes CR, Rhim S, Cheh G. Proximal junctional kyphosis in adult spinal deformity after segmental posterior spinal instrumentation and fusion: minimum five-year follow-up. Spine (Phila Pa 1976) 2008;33:2179-84.

20. Kim HJ, Bridwell KH, Lenke LG, et al. Patients with proximal junctional kyphosis requiring revision surgery have higher postoperative lumbar lordosis and larger sagittal balance corrections. Spine (Phila $\mathrm{Pa}$ 1976) 2014;39:E576-80.

21. Cammarata M, Aubin CE, Wang X, Mac-Thiong JM. Biomechanical risk factors for proximal junctional kyphosis: a detailed numerical analysis of surgical instrumentation variables. Spine (Phila Pa 1976) 2014; 39(8):E500-7.

22. Lowe TG, Kasten MD. An analysis of sagittal curves and balance after Cotrel-Dubousset instrumentation for kyphosis secondary to Scheuermann's disease: a review of 32 patients. Spine (Phila Pa 1976) 1994;19: 1680-5.

23. Denis F, Sun EC, Winter RB. Incidence and risk factors for proximal and distal junctional kyphosis following surgical treatment for Scheuermann kyphosis: minimum five-year follow-up. Spine (Phila Pa 1976) 2009;34:E729-34.

24. Hyun SJ, Rhim SC. Clinical outcomes and complications after pedicle subtraction osteotomy for fixed sagittal imbalance patients: a long-term follow-up data. J Korean Neurosurg Soc 2010;47:95-101.

25. Kim HJ, Bridwell KH, Lenke LG, et al. Proximal junctional kyphosis results in inferior SRS pain subscores in adult deformity patients. Spine (Phila Pa 1976) 2013;38:896-901.

26. Watanabe K, Lenke LG, Bridwell KH, Kim YJ, Koester L, Hensley M. Proximal junctional vertebral frac- ture in adults after spinal deformity surgery using pedicle screw constructs: analysis of morphological features. Spine (Phila Pa 1976) 2010;35:138-45.

27. Hart RA, Prendergast MA, Roberts WG, Nesbit GM, Barnwell SL. Proximal junctional acute collapse cranial to multi-level lumbar fusion: a cost analysis of prophylactic vertebral augmentation. Spine J 2008;8:875-81.

28. Smith MW, Annis P, Lawrence BD, Daubs MD, Brodke DS. Early proximal junctional failure in patients with preoperative sagittal imbalance. Evid Based Spine Care J 2013;4:163-4.

29. Ha Y, Maruo K, Racine L, et al. Proximal junctional kyphosis and clinical outcomes in adult spinal deformity surgery with fusion from the thoracic spine to the sacrum: a comparison of proximal and distal upper instrumented vertebrae. J Neurosurg Spine 2013;19:360-9.

30. Kim YJ, Bridwell KH, Lenke LG, Rhim S, Kim YW. Is the T9, T11, or L1 the more reliable proximal level after adult lumbar or lumbosacral instrumented fusion to L5 or S1? Spine (Phila Pa 1976) 2007;32:265361.

31. Scheer JK, Lafage V, Smith JS, et al. Maintenance of radiographic correction at 2 years following lumbar pedicle subtraction osteotomy is superior with upper thoracic compared with thoracolumbar junction upper instrumented vertebra. Eur Spine J 2015;24 Suppl 1:S121-30.

32. Fujimori $\mathrm{T}$, Inoue $\mathrm{S}$, Le $\mathrm{H}$, et al. Long fusion from sacrum to thoracic spine for adult spinal deformity with sagittal imbalance: upper versus lower thoracic spine as site of upper instrumented vertebra. Neurosurg Focus 2014;36:E9.

33. Hassanzadeh H, Gupta S, Jain A, El Dafrawy MH, Skolasky RL, Kebaish KM. Type of anchor at the proximal fusion level has a significant effect on the incidence of proximal junctional kyphosis and outcome in adults after long posterior spinal fusion. Spine Deform 2013;1:299-305.

34. Kuhns CA, Bridwell KH, Lenke LG, et al. Thoracolumbar deformity arthrodesis stopping at L5: fate of the L5-S1 disc, minimum 5-year follow-up. Spine (Phila Pa 1976) 2007;32:2771-6.

35. Hirsch BP, Unnanuntana A, Cunningham ME, Lane JM. The effect of therapies for osteoporosis on spine fusion: a systematic review. Spine J 2013;13:190-9.

36. Ohtori S, Inoue G, Orita $S$, et al. Teriparatide accel- 
erates lumbar posterolateral fusion in women with postmenopausal osteoporosis: prospective study. Spine (Phila Pa 1976) 2012;37:E1464-8.

37. Ohtori $S$, Inoue $G$, Orita $S$, et al. Comparison of teriparatide and bisphosphonate treatment to reduce pedicle screw loosening after lumbar spinal fusion surgery in postmenopausal women with osteoporosis from a bone quality perspective. Spine (Phila Pa 1976) 2013;38:E487-92.

38. Kebaish KM, Martin CT, O'Brien JR, LaMotta IE, Voros GD, Belkoff SM. Use of vertebroplasty to prevent proximal junctional fractures in adult deformity surgery: a biomechanical cadaveric study. Spine J 2013;13:1897-903.

39. Fernandez-Baillo N, Sanchez Marquez JM, Sanchez Perez-Grueso FJ, Garcia Fernandez A. Proximal junctional vertebral fracture-subluxation after adult spine deformity surgery: does vertebral augmentation avoid this complication? A case report. Scoliosis 2012;7:16.

40. Yagi M, Rahm M, Gaines R, et al. Characterization and surgical outcomes of proximal junctional failure in surgically treated patients with adult spinal deformity. Spine (Phila Pa 1976) 2014;39:E607-14. 